\title{
Perancangan Animasi 3D Sebagai Media Promosi Rumah Pada PT. Prima Inti Nusa
}

\author{
Andrian \\ Politeknik Negeri Media Kreatif, Jakarta, Indonesia \\ Email : andrian@polimedia.ac.id
}

\begin{abstract}
ABSTRAK
Rumah merupakan harta terbesar bagi keluarga dan merupakan tempat tinggal paling utama. Dalam mempromosikan rumah, tentunya sangat banyak media promosi yang dipakai seperti media cetak atau media elektronik. PT. Prima Inti Nusa adalah perusahaan yang bergerak dibidang properti dan pemasaran rumah. Selama ini perusahaan menggunakan media cetak sebagai media promosi yang memiliki banyak keterbatasan seperti calon pembeli tidak mengetahui informasi lebih mengenai detail rumah yang akan dibeli. Untuk itu, dengan membuat animasi 3D sebagai media promosi rumah pada PT. Prima Inti Nusa diharapkan mampu meningkatkan penjualan. Animasi 3D ini dibuat melalui tiga tahapan yaitu pra produksi, produksi, dan pasca produksi. Proses pengerjaan animasi 3D menggunakan software Sketchup Pro 2016, Lumion 6, dan Adobe Premiere Pro CC 2015. Output yang dihasilkan berupa sebuah animasi 3D sebagai media promosi rumah pada PT. Prima Inti Nusa yang menampilkan exterior dan interior rumah.
\end{abstract}

Kata Kunci : Animasi, Promosi, Animasi 3D

\begin{abstract}
The house is the greatest treasure for the family and is the most important place to live. In promoting the house, of course, there are a lot of promotional media used such as print media or electronic media. PT. Prima Inti Nusa is a company engaged in property and home marketing. So far, the company uses print media as a promotional medium which has many limitations such as potential buyers not knowing more information about the details of the house to be purchased. For that, by making 3D animation as a home promotion media at PT. Prima Inti Nusa is expected to increase sales. This 3D animation is made in three stages, namely pre-production, production, and post-production. The process of working on 3D animation uses Sketchup Pro 2016, Lumion 6, and Adobe Premiere Pro CC 2015 software. The resulting output is a 3D animation as a home promotion medium at PT. Prima Inti Nusa, which features the exterior and interior of the house.
\end{abstract}

Key Words : Animation, Promotion, Animation 3D 


\section{PENDAHULUAN}

Beberapa tahun belakangan ini, perkembangan teknologi multimedia khususnya animasi di Indonesia mengalami kemajuan yang cukup pesat. Faktor terbesar yang mendorong kemajuan teknologi multimedia di Indonesia adalah industri kreatif. Teknologi multimedia yang semakin berkembang ini, membuat semua bidang industri di Indonesia membutuhkan multimedia sebagai media baru dalam memasarkan dan mempromosikan suatu produk. Bentuk teknologi yang berkembang saat ini adalah animasi 3D.

Animasi 3D merupakan penciptaan gambar bergerak dalam ruang digital tiga dimensi. Animasi 3D sebagai media promosi sangat populer dikenal oleh kalangan masyarakat karena tampilan informasi yang disajikan sangat realistis sehingga dapat terlihat lebih nyata dan mendekati objek yang sebenarnya, (Gunawan, (2013:30). Pada saat ini, perusahaan-perusahaan yang bergerak dibidang properti rumah sangat membutuhkan animasi 3D, agar mereka mampu bersaing dengan perusahaan yang bergerak dibidang yang sama.

Media promosi merupakan suatu alat untuk mengkomunikasikan suatu produk dan jasa, agar dapat dikenal masyarakat lebih luas. Promosi dalam bentuk apapun merupakan suatu usaha untuk mempengaruhi pihak lain, (Setyaningrum, 2015:224). Dalam pembuatan karya tugas akhir ini, nantinya brosur perumahan akan dipromosikan melalui media elektronik.

PT. Prima Inti Nusa yang bergerak dibidang properti dan pemasaran rumah, memiliki masalah dalam pemasaran rumah kepada calon pembeli. Tim marketing yang bertugas melakukan pemasaran rumah hanya dengan media brosur sehingga calon pembeli tidak mendapatkan informasi yang akurat dari rumah yang dipasarkan. Untuk itu peneliti merancang dan mengusulkan media yang dapat memberikan informasi yang akurat kepada calon pembeli dari rumah yang dipasarkan oleh tim marketing yaitu Animasi 3D.

\section{TINJAUAN PUSTAKA}

\subsection{Multimedia}

Multimedia sendiri dari dua kata yaitu multi (bahasa latin) yang berarti banyak dan medium (bahasa latin) yang berarti perantara. Pengertian multimedia menurut Vaughan (2011:9), adalah kombinasi dari teks, gambar, animasi, suara, dan video yang telah dimanipulasi oleh komputer atau alat elekrtonik lainnya. Dapat disimpulkan bahwa pengertian multimedia adalah gabungan dari beberapa unsur perantara yaitu teks, gambar, suara, video dan animasi yang berguna untuk menyampaikan suatu informasi atau suatu tujuan kepada publik melalui proses manipulasi komputer.

\subsection{Animasi Tiga Dimensi (3D)}

Animasi berasal dari kata "to animate" yang artinya membuat seolah-olah hidup dan bergerak. Pengertian animasi adalah film yang berasal dari gambar-gambar yang diolah sedemikian rupa hingga menjadi sebuah gambar bergerak dan bercerita, (Gunawan, 2013:26).

Menurut Vaughan (2011:29), animasi adalah usaha untuk membuat visual statis menjadi hidup. Animasi merupakan perubahan visual sepanjang waktu yang memberikan kekuatan besar pada proyek multimedia dan halaman web yang dibuat. 


\subsection{Media Promosi}

Promosi adalah kegiatan mendekatkan produk kepada pembeli agar mereka tertarik sebelum terlanjur memilih produk lain. Caranya sangat beragam antara lain dengan penjualan langsung (direct selling), periklanan (advertising), dan publisitas (marketing publik relation), atau memberikan tambahan daya tarik seperti penjualan berhadian (sales promotion), (Ngangi, 2010:73).

Pengertian promosi menurut Kinnear dan Kenneth (2015:223) dalam Setyaningrum dkk, mendefinisikan promosi sebagai sebuah mekanisme komunikasi pemasaran, pertukaran informasi antara pembeli dan penjual. Promosi berperan menginformasikan (to inform), membujuk (to persuade), dan mengingatkan (to remind) kepada konsumen agar menanggapi (respond) produk atau jasa yang ditawarkan. Tanggapan yang diinginkan dapat berbagai bentuk, dari kesadaran (awareness) akan keberadaan produk atau jasa sampai pembelian yang sederhana. Sedangkan menurut Setyaningrum (2015:224), promosi dalam bentuk apapun merupakan suatu usaha untuk mempengaruhi pihak lain.

\section{HASIL DAN IMPLEMENTASI}

\subsection{Pra Produksi}

Pada tahap pra produksi, ada beberapa persiapan yang harus dilakukan untuk menuju ke tahap produksi seperti ide cerita, sinopsis, objek utama, environment dan storyboard

\section{Story Board}

Storyboard merupakan sketsa gambar yang disusun berurutan sesuai dengan cerita, sehingga kita dapat lebih memahami dan mempermudah pekerjaan dalam penyuntingan animasi, dan menentukan gerakan yang sesuai dengan objek yang tersedia, dan menyesuaikan berapa lama durasi yang telah ditentukan

\begin{tabular}{|l|l|l|}
\hline \multicolumn{1}{|c|}{ Scene 1 } & Durasi: 10 detik & Keterangan \\
\hline & Zoom In, Panning Right \\
\hline
\end{tabular}




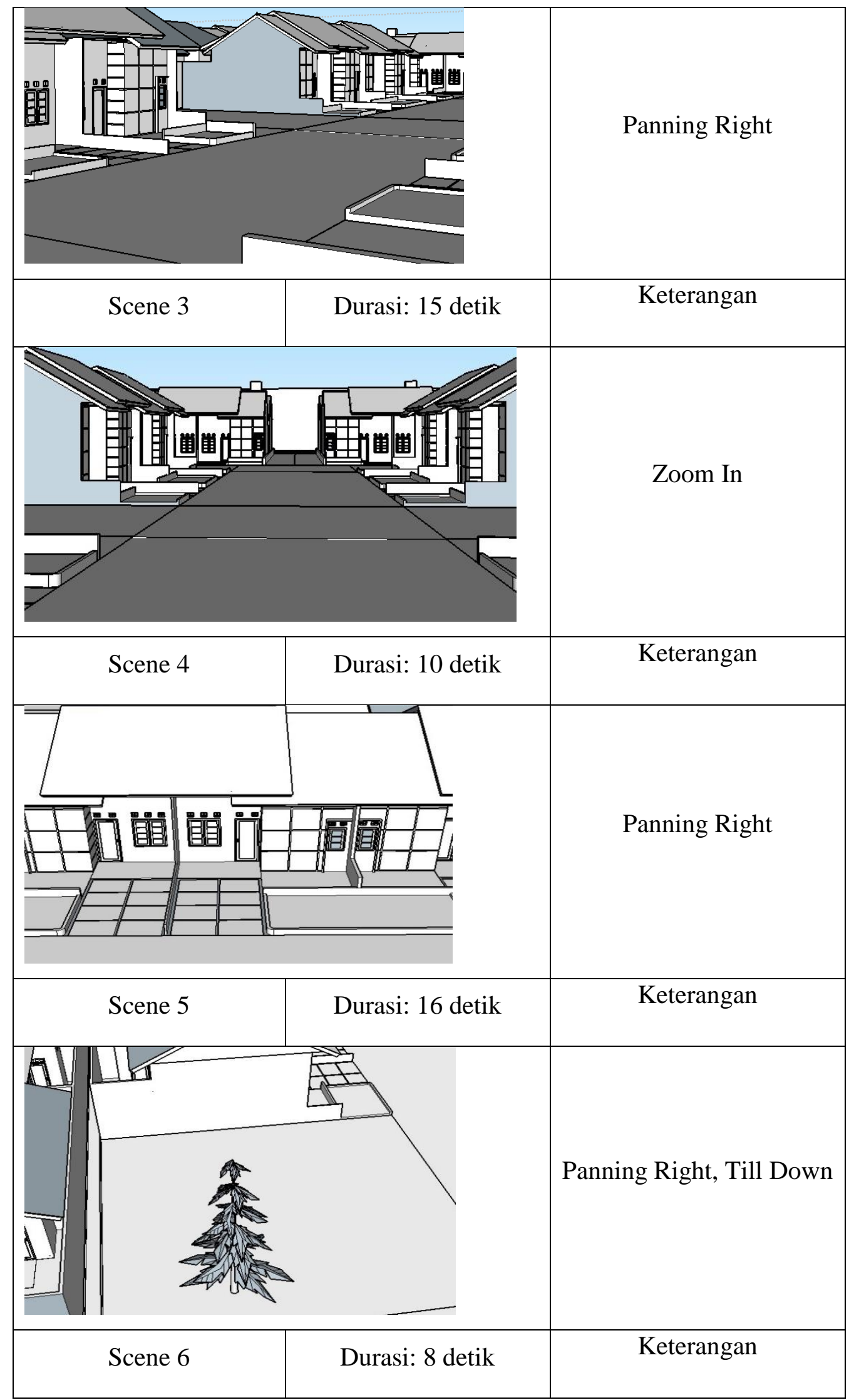




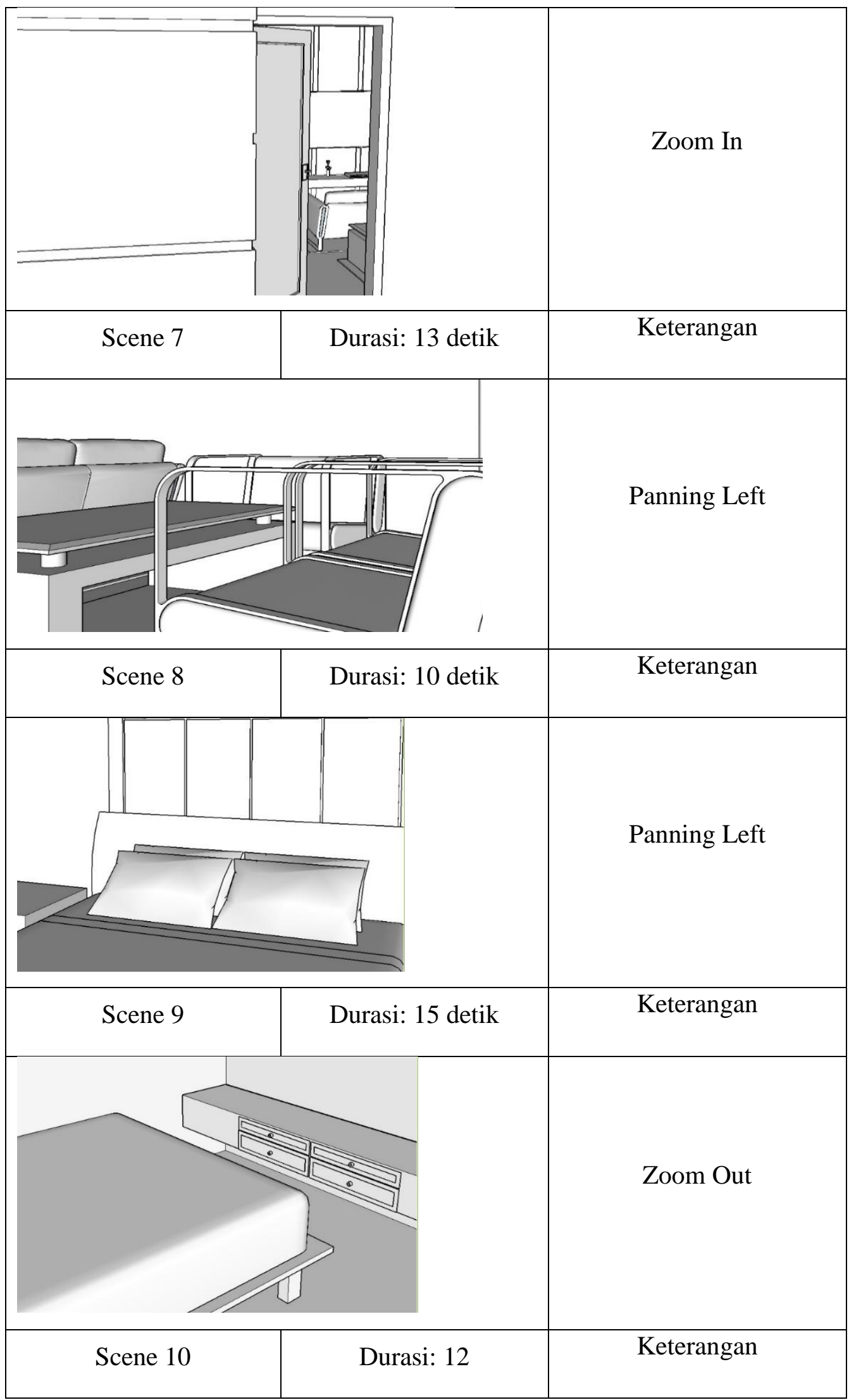




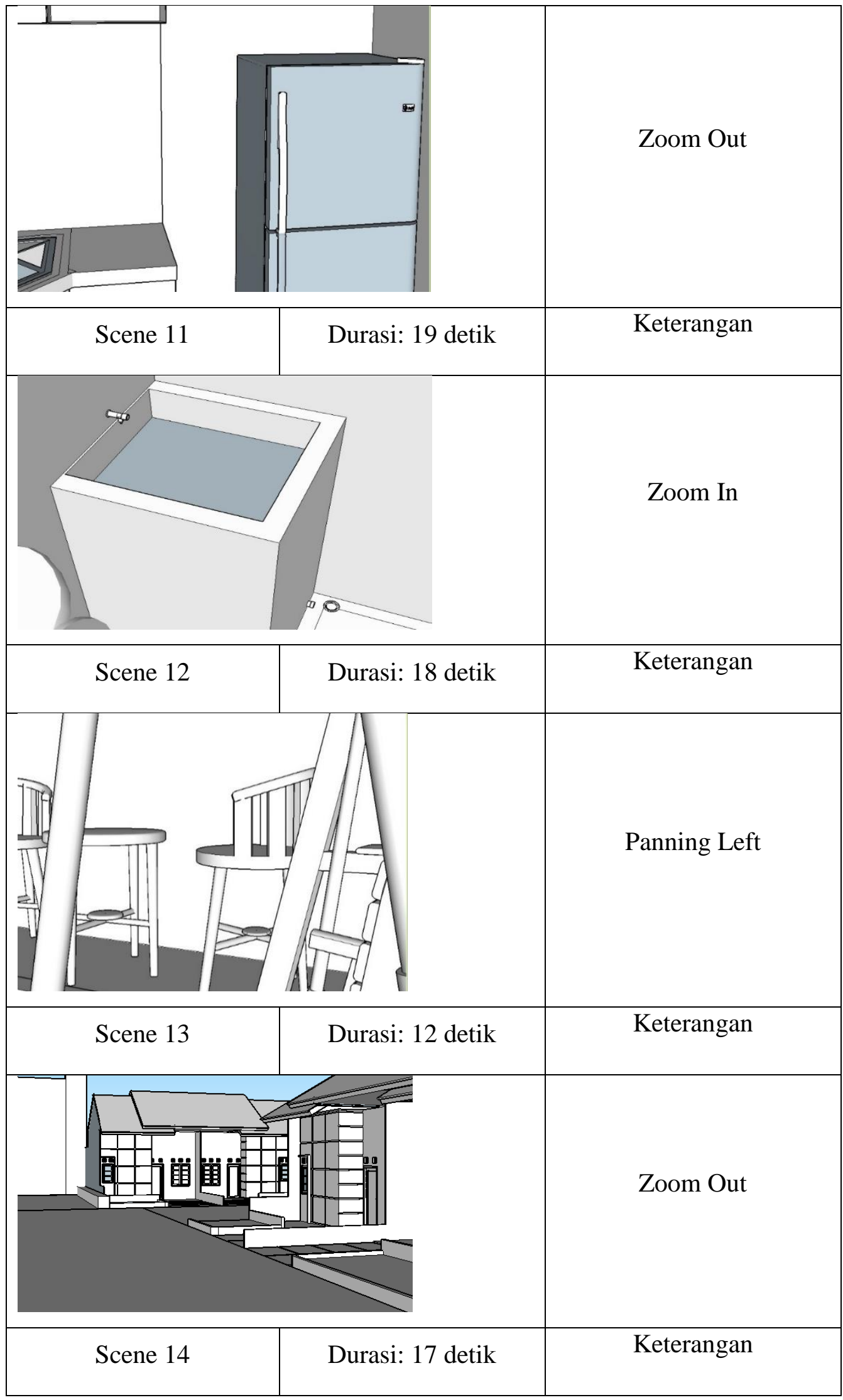




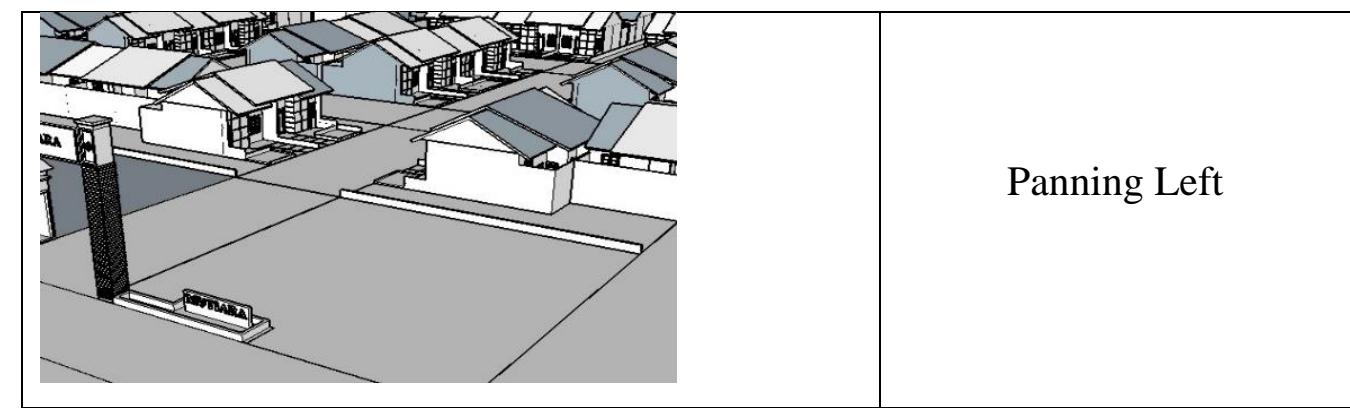

Produksi

Pada tahap produksi ini langkah-langkah yang dilakukan yaitu modeling exterior rumah, modeling interior rumah, texturing, lighting, animation, pemberian effect, dan rendering animation. Di tahapan modeling exterior, interior, dan texturing awal, penulis melakukannya di software Sketchup Pro 2016, lalu pada tahap texturing akhir, lighting, animation, pemberian effect, dan rendering animation, penulis melakukannya dengan software Lumion 6.

\subsubsection{Modelling Exterior}

1. Sketsa Rumah

Sketsa rumah merupakan gambar atau goresan yang dibuat secara manual di atas kertas, maka bisa dilihat seperti di bawah ini:

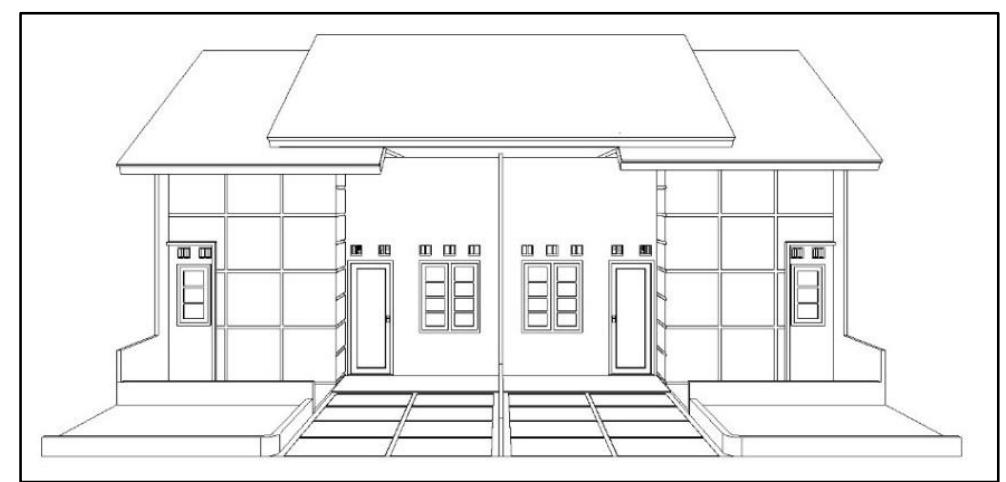

Gambar 1. Sketsa Rumah Tipe 36

\subsection{Modeling Rumah}

Dalam pembuatan 3D modeling rumah dengan software Sketchup, tahap ini mengikuti dari 3D modeling layout yang telah dibuat, kemudian dibentuk dengan teknik extrude atau push/pull serta dengan beberapa teknik lainnya. Berikut tampilan dari 3D modeling rumah: 


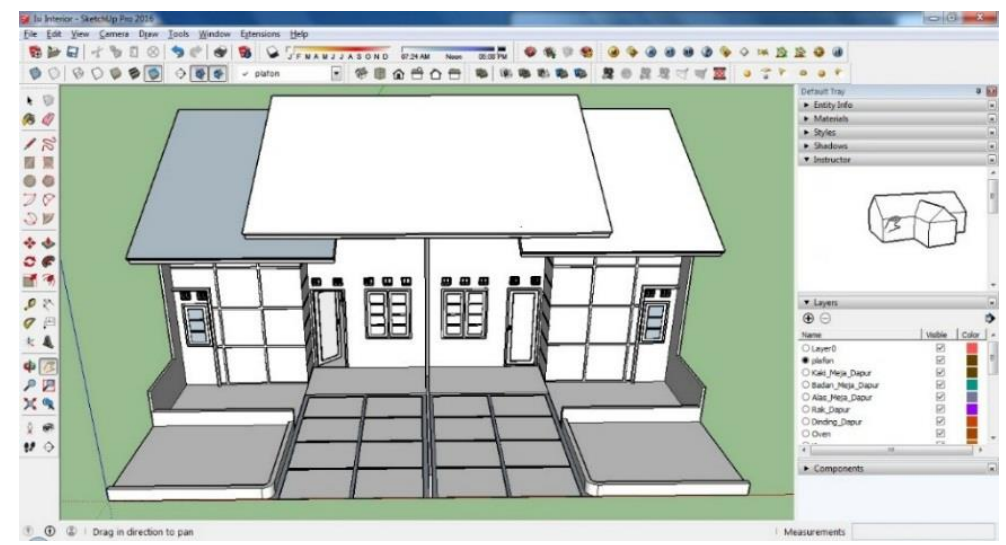

Gambar 2. Modeling Rumah Tipe 36

\section{Texturing}

Setelah tahap modeling selesai dilakukan, lalu masuk ketahap texturing yaitu pemberian warna dan tekstur pada model 3D dengan menggunakan material kemudian penyuntingan material yang sesuai dengan kebutuhan. Berikut ini gambar teksturing tahap awal pada software Sketchup:

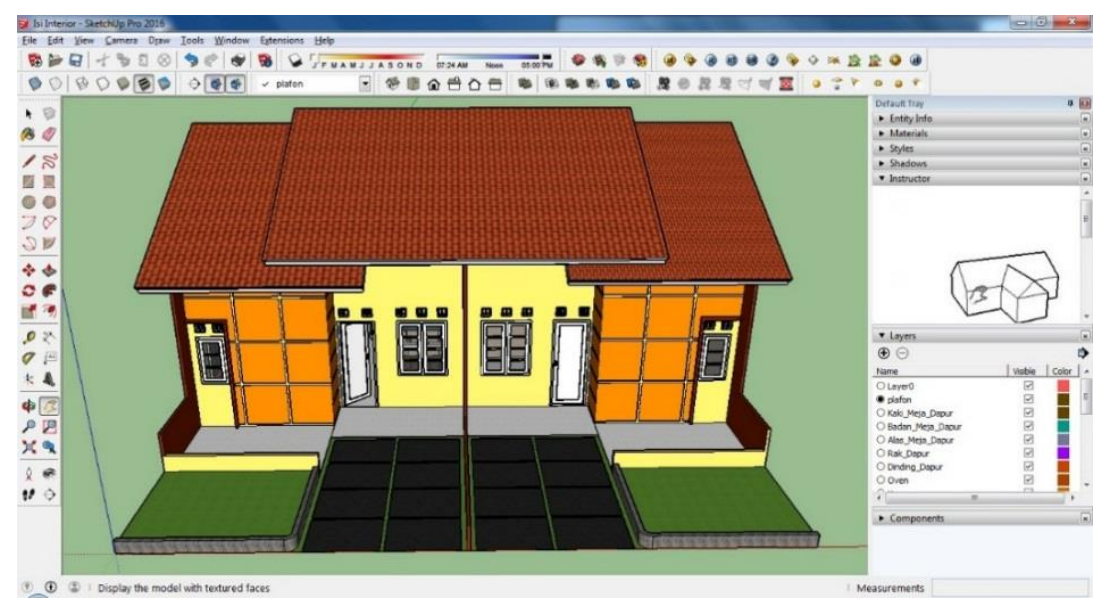

Gambar 3. Texturing Exterior Dengan Sketchup

Tahap texturing dilakukan dua kali ketika memasuki tahap akhir, pemberian texturing ini kerjakan di software Lumion 6, karena pemberian material di Lumion 6 lebih terlihat realistis. Berikut gambar modeling exterior rumah yang telah diberi tekstur: 


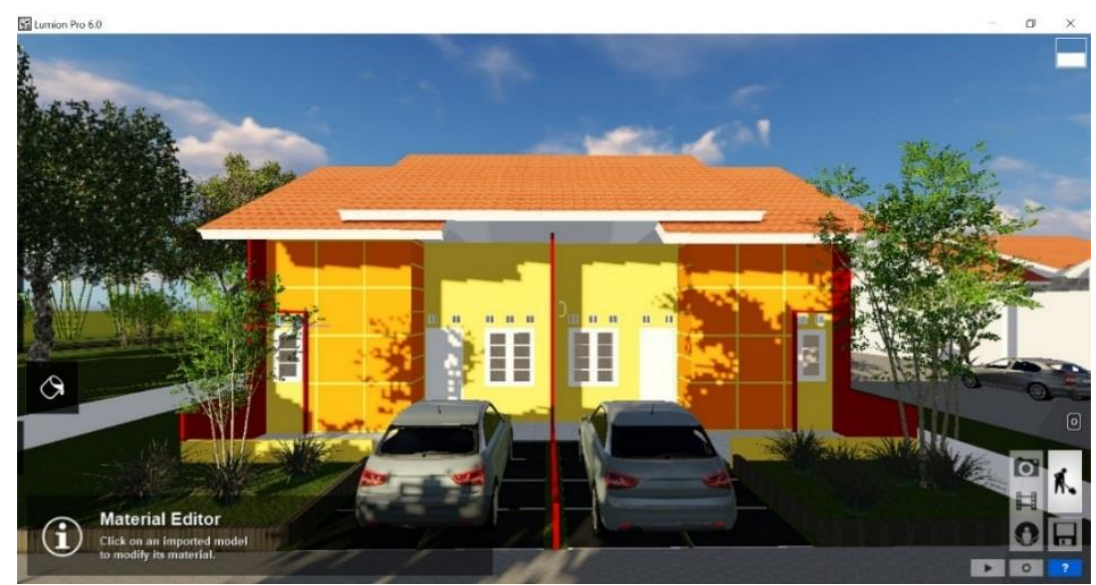

Gambar 4.. Texturing Exterior Dengan Lumion

\subsubsection{Modeling Interior}

Interior merupakan tampilan dalam atau isi rumah dari ruang tamu, kamar tidur, dapur, dan kamar mandi. Modeling interior memfokuskan penataan dan pemilihan komponen pendukung pada isi rumah, seperti sofa, tv, tempat tidur, lampu, toilet duduk, dan lain sebagainya. Berikut ini tampilan dari interior rumah.

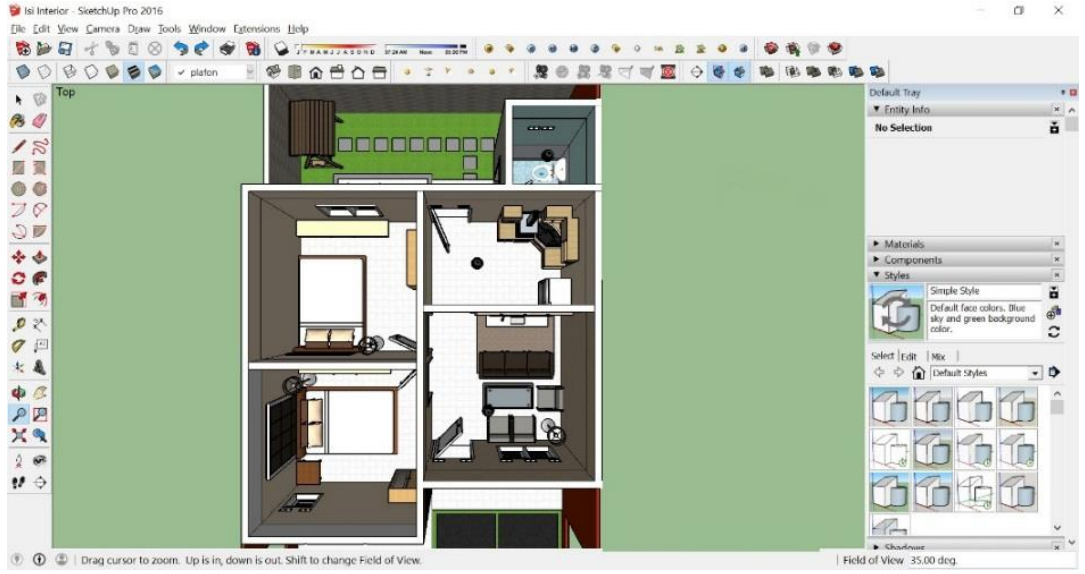

Gambar 5. Modeling Interior Rumah

\subsubsection{Animating}

Animating merupakan tahap dimana melakukan pergerakan animasi dengan menggunakan panduan dari storyboard yang telah disusun dengan penentuan durasi yang telah ditetapkan. Pergerakan yang dibuat yaitu dengan mengambil satu dambar dan satu gambar yang berbeda, maka akan menghasilkan sebuah pergerakan kamera dari software Lumion 6. Berikut adalah tampilan kerja dari pembuatan pergerakan kamera: 


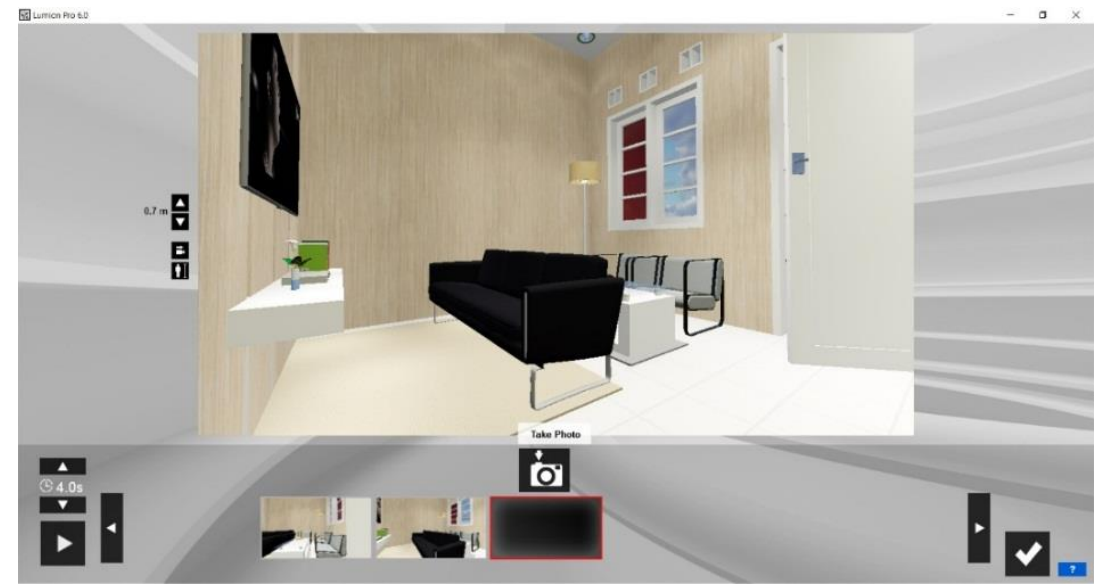

Gambar 6. Pergerakan Kamera

Ada beberapa titik view yang telah ditetapkan berupa efek objek bergerak yaitu mass move effect pada animasi, berikut contohnya:

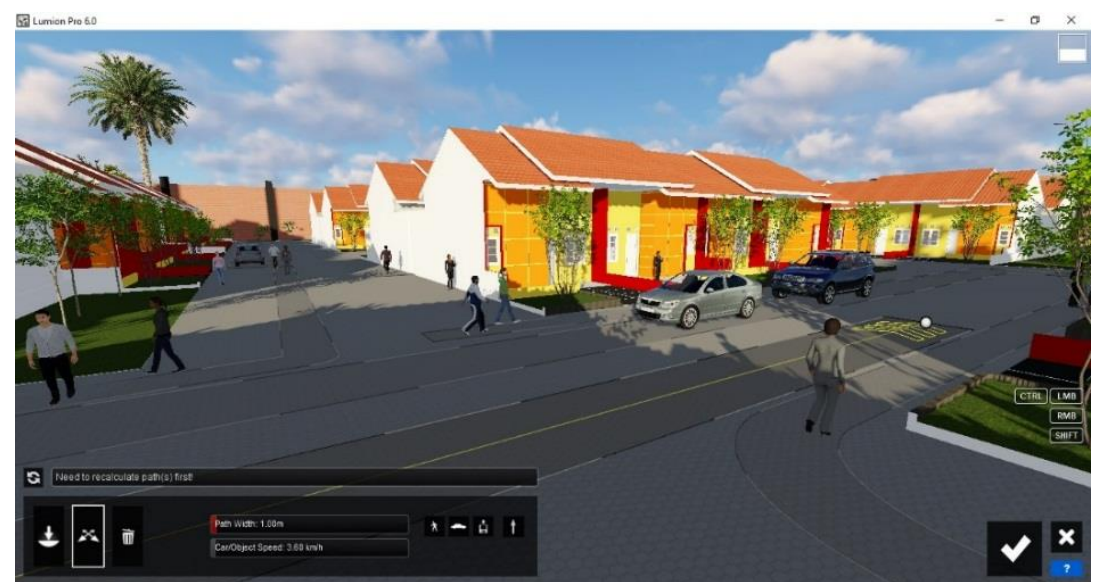

Gambar 7. Mass Move Effect

Pada bagian interior rumah penulis memberikan efek pintu terbuka yaitu menggunakan efek advanced move pada animasi, animasi key frame ini sangat mudah digunakan hanya dengan mengatur timing yang tepat, berikut contohnya:

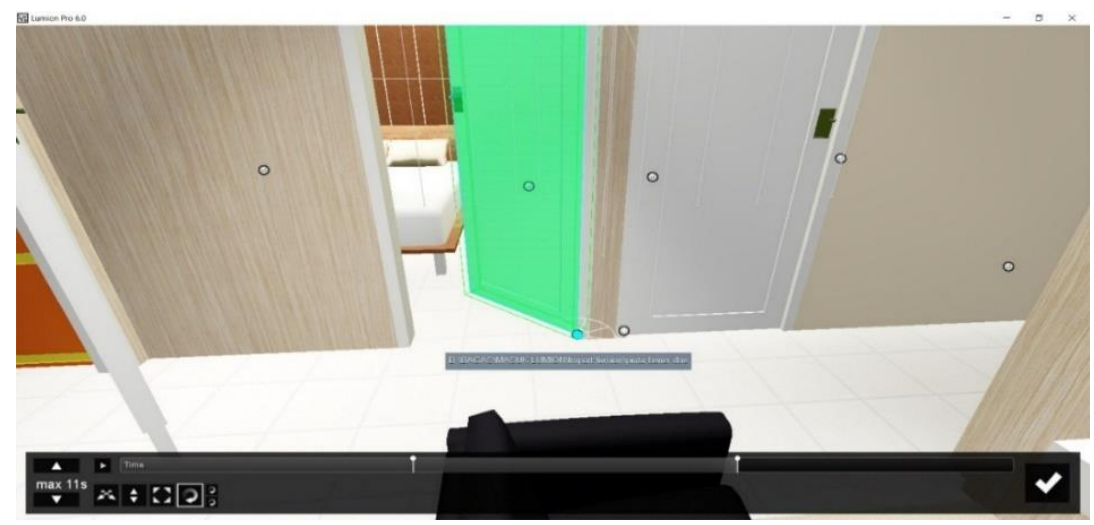

\subsection{Pasca Produksi}

Gambar 8. Advanced Move 
Pasca produksi adalah tahapan dimana proses penyuntingan dari semua hasil export animasi yang berupa video digabungkan dengan software Adobe Premiere Pro 2016 lalu di satukan dan menjadi satu video.

\section{Opening (Pembuka)}

Pada tampilan opening berupa judul perumahan yang dibuat dengan software Adobe Premiere Pro CC 2015. Tampilannya sebagai berikut:

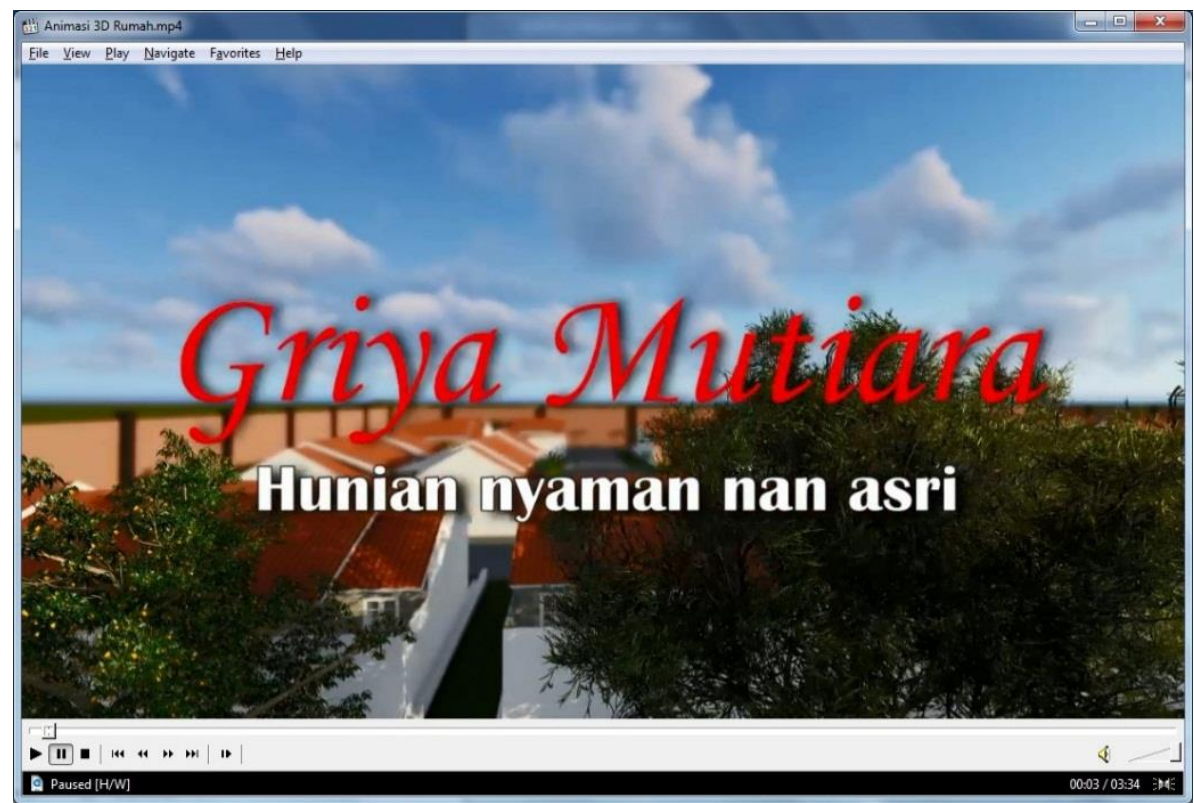

Gambar 9. Tampilan Opening

\section{Tampilan Exterior}

Tampilan exterior merupakan tampilan yang berupa animasi perumahan bagian luar. Berikut ini tampilannya:

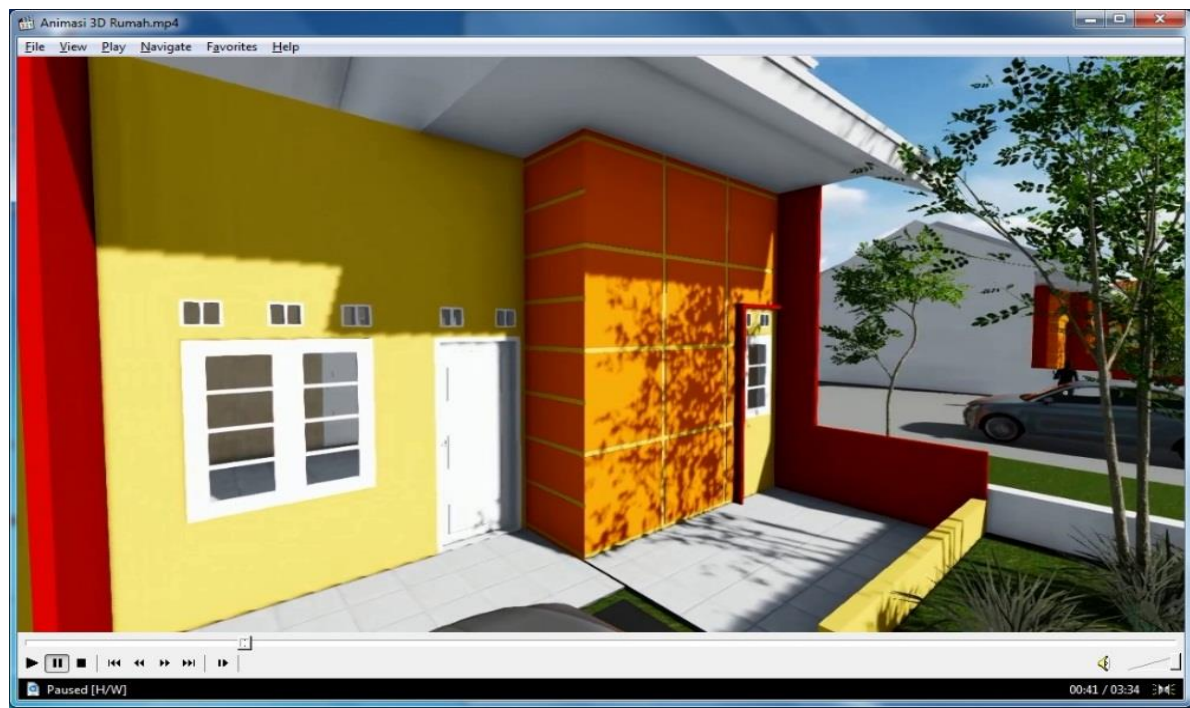

Gambar 10. Tampilan Exterior

3. Tampilan Interior

Tampilan interior merupakan tampilan animasi bagian dalam rumah. 


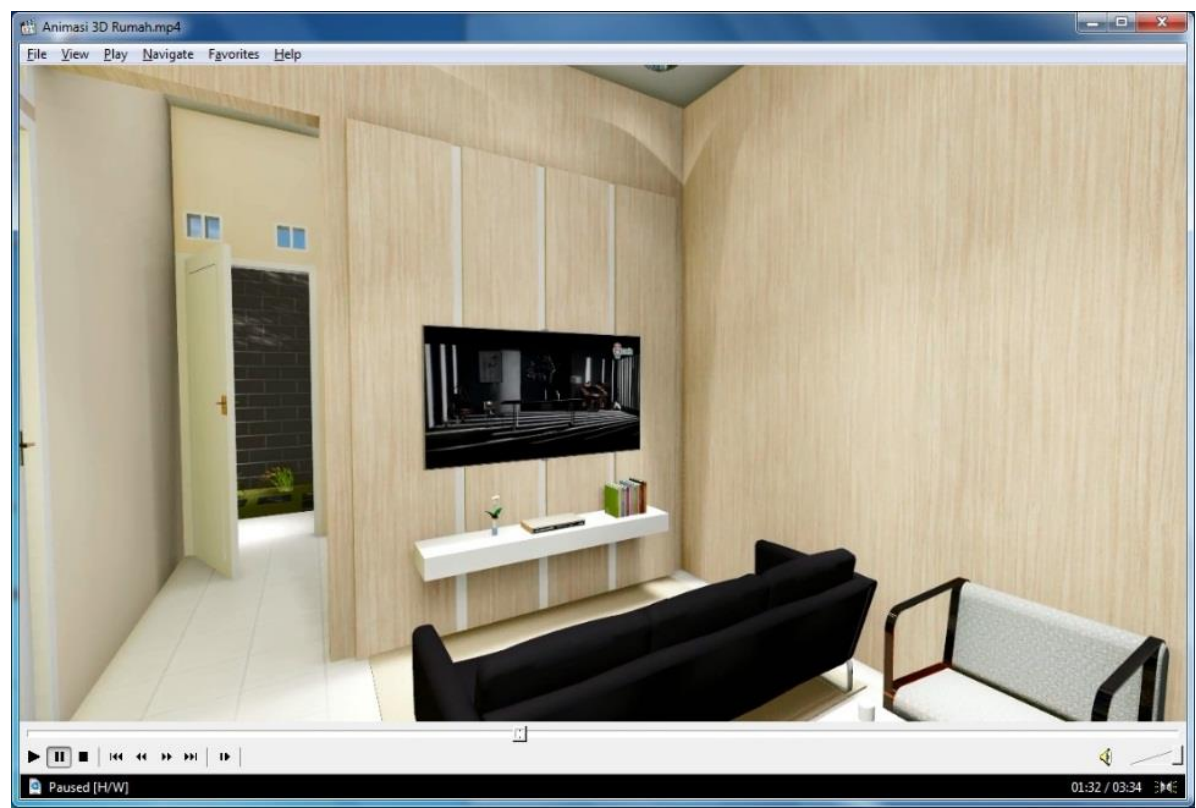

Gambar 11. Tampilan Interior

\section{KESIMPULAN}

Kesimpulan yang diperoleh dalam Perancangan Animasi 3D Sebagai Media Promosi Rumah Pada PT. Prima Inti Nusa" adalah sebagai berikut:

1. Dalam perancangan animasi 3D sangat membutuhkan konsep yang baik agar animasi 3D yang dihasilkan lebih maksimal, terutama pada pembuatan animasi perumahan dibutuhkan kemampuan modeling dan arahan kamera yang sangat baik agar menghasilkan objek yang realistis atau nyata.

2. Untuk merancang animasi 3D yang digunakan sebagai media promosi, diperlukan riset tentang perusahaan dan perumahan yang akan dipromosikan dan bagaimana mengaplikasikannya ke dalam hasil jadi yaitu berupa animasi 3D.

3. Animasi 3D promosi rumah ini berfungsi sebagai media promosi yang lebih baik, dan lebih mudah dipahami oleh tim marketing perusahaan maupun calon pembeli.

\section{DAFTAR PUSTAKA}

[1] Gunawan, Bambi Bambang. 2013. Nganimasi Bersama Mas Be!. Jakarta: PT Elex Media Komputindo

[2] Kementerian Pekerjaan Umum dan Perumahan Rakyat. 2011. Undang-Undang Nomor 1 Tahun 2011 Tentang Perumahan dan Kawasan Permukiman. Jakarta

[3] Manullang, Rio. 2006. Desain Fasade Dan Denah Rumah 1 \& 2 Lantai. Jakarta : PT Elex Media Komputindo

[4] Nafisah, Syifaun. 2003. Grafika Komputer. Yogyakarta : Graha Ilmu

[5] Ngangi, Evie. 2010. Lekuk Liku Bisnis Pendidikan. Jakarta : PT Elex Media Komputindo

[6] Putri, Galih PS. 2014. Hunian Hurban Bergaya Town House. Jakarta : Transmedia Pustaka

[7] Setyaningrum, Ari. 2015. Prinsip-Prinsip Pemasaran. Yogyakarta : Andi Offset 
[8] Suyanto, M. 2004. Analisis \& Desain Aplikasi Multimedia untuk Pemasaran. Yogyakarta: Andi

[9] Vaughan, Tay. 2011. Multimedia: Making It Work. 8th Edition. New York : McGraw Hill

[10] Yatini, Indra. 2010. Flowchart, Algoritma dan Pemrograman Menggunakan Bahasa C++ Builder. Yogyakarta : Graha Ilmu 